\title{
“Don't Tell Me What to Do": Resistance to Climate Change Messages Suggesting Behavior Changes
}

\author{
Risa Palm, ${ }^{\mathrm{a}}$ TOBy Bolsen, ${ }^{\mathrm{b}}$ AND Justin T. KingSLAND ${ }^{\mathrm{b}}$ \\ ${ }^{\mathrm{a}}$ Urban Studies Institute, Georgia State University, Atlanta, Georgia; ${ }^{\mathrm{b}}$ Department of Political Science, Georgia State University, \\ Atlanta, Georgia
}

(Manuscript received 15 November 2019, in final form 4 August 2020)

\begin{abstract}
This study evaluates the impact of exposure to messages that emphasize the need for changes in individual behavior or in public policy to address climate change attributed to a "climate scientist" or to an unnamed source. We implemented a large survey experiment $(N=1915)$ online through Amazon's Mechanical Turk (MTurk) platform that manipulated the presence of recommendations for voluntary behavioral changes or the adoption of new laws to mitigate climate change. We found that, regardless of the source of the information, recommendations for behavioral changes decreased individuals' willingness to take personal actions to reduce greenhouse gases, decreased willingness to support proclimate candidates, reduced belief in the accelerated speed of climate change, and decreased trust in climate scientists.
\end{abstract}

KEYWORDS: Social Science; Climate change; Communications/decision making

\section{Introduction}

Climate change arguably presents the most challenging collective action problem the world has ever faced. Rising global temperatures due to the increasing accumulation of greenhouse gases in the atmosphere will fundamentally reshape societies, threatening economies, health care systems, and geopolitical relations. It is projected that state-of-the-art behavioral interventions, such as providing targeted information to consumers about high-impact individual and household energy choices, could significantly reduce greenhouse gas emissions in the United States over time (Dietz et al. 2009; Capstick et al. 2014; Stern 2020); however, such reductions may be difficult to achieve in practice due to a lack of public (political) support for specific proenvironmental policies (Druckman 2015; Nielsen et al. 2020b; van der Linden 2016). In this context, it is crucial to understand how best to promote high-impact individual and collective actions to mitigate the effects that will occur as a result of climate change. How effective are direct messages that recommend changes in personal behavior or the enactment of new laws to reduce emissions? Does the impact of such a message depend on the presence of an expert source linked to the recommendations?

A large body of research has been accumulated that shows that exposure to strategic frames and persuasive messages can influence perceptions and willingness to support various actions to address climate change (Bolsen and Shapiro 2017; Druckman and McGrath 2019; Hart and Feldman 2016; van der Linden 2017). However, few studies have investigated the impact of exposure to messages that recommend specific changes in individual behaviors such as reducing beef consumption or cutting back on air travel as ways to reduce global carbon emissions (Nielsen et al. 2020a) as well as collective policies such as increasing taxes on carbon emissions and increasing vehicle fuel efficiency requirements. Do people

Corresponding author: Toby Bolsen, tbolsen@gsu.edu become more willing to change their behaviors or support specific proclimate candidates and policies following exposure to framed messages emphasizing the need for such actions? When climate scientists engage in what may be viewed as "political advocacy" by recommending specific "solutions," does this have an impact on the degree to which the public trusts them to provide impartial and unbiased information about climate change? Do the effects of exposure to such messages depend on individual characteristics such as a person's party identification?

The present study examines the response to framed messages that advocate both changes in individual behavior including, for example, taking fewer plane flights and using less hot water, as well as collective actions such as retrofitting buildings or halting deforestation to address the impacts of climate change. Responses reported include willingness to engage in personal actions to reduce greenhouse gas emissions, stated preference to vote for a candidate who would enact proclimate legislation, belief that human activity is the cause of accelerated global warming, and trust in climate scientists. To illuminate these relationships, we implemented a survey experiment $(N=1915)$ online through Amazon's Mechanical Turk (MTurk) platform that manipulated 1) the presence of recommendations for changes in public policy or individual behavior in order to reduce emissions of greenhouse gases, and 2) the presence of a subtle source cue attributing these recommendations to climate scientists. The experiment thus dealt with two aspects of climate communication: the differences in the response to a message recommending collective policies or personal sacrifices as a way to mitigate climate change, and 3) the introduction of a source manipulation that attributed the recommendation to a generic climate scientist. We find that presenting individuals with framed messages that advocate personal behavioral changes to combat climate change, with or without an expert source cue, reduces their expressed willingness to take action, decreases support for proclimate candidates, decreases belief in the scientific consensus, and lowers 
trust in climate scientists. We address some of the implications of these findings for debates regarding how best to mobilize collective action to combat climate change as well as the role of climate scientists in policy advocacy.

\section{a. Solution framing and climate action}

The concept of "climate action" refers both to individual behavioral changes to voluntarily reduce emissions or support for government actions to accomplish this goal (Lubell et al. 2007; Zahran et al. 2006). It has been estimated, for instance, that greenhouse gas emissions would be reduced considerably if consumers could be persuaded (collectively) to substitute meat and dairy with plant-based foods in their diet (Green et al. 2015; Poore and Nemecek 2018). Yet people often hold misperceptions about the personal actions that would be most effective at reducing climate pollution (Bord et al. 1998; Bostrom et al. 1994; Kempton 1991; Sterman and Sweeney 2007; Whitmarsh 2009).

When individuals are exposed to communications that emphasize specific considerations about climate change, such as recommendations to engage in climate-friendly behaviors or support proclimate policies, they may prioritize the highlighted consideration when forming their opinion, often shifting their opinion in the direction of the message; this is referred to as an emphasis framing effect (Druckman 2011). Prior research has found that exposure to messages that highlight descriptive social norms (Bolsen 2013; Bolsen et al. 2014b; Mildenberger and Tingley 2019; van der Linden 2016), the benefits or costs of climate policies (Levine and Kline 2017, 2019), the benefits or costs of personal actions (Bolsen et al. 2014a), or the details of specific climate policy proposals (Buntaine and Prather 2018) can influence people's willingness to engage in or support collective actions aimed at reducing climate change.

Despite robust empirical findings showing the direct impact of messages on changing both attitudes and behavior in the direction of the message (Chong and Druckman 2007), there are also several reasons why specific types of messages might not be effective. First, most people value freedom of choice, particularly in decisions they make in their everyday lives (Perlmuter et al. 1980; Fujiwara et al. 2013). Several empirical studies have found that a behavior change as personal as a change in diet is met with particular resistance, even among those who ardently favor action to mitigate global climate change (Attari et al. 2011; DeBoer et al. 2013). Several factors may come into this resistance but among them is the concept of psychological "reactance," which may be triggered when people perceive their freedom of choice is impinged upon by directives from others (Gifford et al. 2011; Gifford 2011; Ma et al. 2019; Nisbet et al. 2015).

Second, rather than take personal responsibility for an issue as large as climate change, many people would prefer an "upstream" solution that would not impinge on their personal behavior; even many of those who believe that climate mitigation is urgent would prefer that the producers rather than the consumers of carbon be regulated or taxed (Campbell and Sedikides 1999; Hardisty et al. 2019). The results of these empirical studies suggest that at least some respondents are more likely to favor more distant policy solutions that do not have a direct impact on their personal behavior.

Third, addressing large-scale collective action problems may require generating support for policies that have been politicized on ideological grounds because they involve the regulation of free markets or potential restrictions on personal freedoms. Surveys have shown that Americans are divided over support for public policy to mitigate climate change, with liberal Democrats as opposed to conservative Republicans more likely to support tougher fuel efficiency standards and various tax incentives even if this means greater costs to themselves or their families (Nisbet et al. 2015; Pew Research Center 2018). Campbell and Kay (2014) have suggested that to protect their values and cultural worldviews, conservatives might not only oppose specific climate change mitigation strategies but also deny that climate change itself is a problem: in other words, when confronted with solutions to climate change that would pose regulations, supporters of free-market solutions will respond by denying that climate change exists, not because of their perception of the "inherent seriousness" of the threat but because they oppose on ideological grounds the solutions that are generally proposed to address it.

Fourth, there are questions about the efficacy of voluntary adoption of individual-level behavior changes when Earth is confronted with a problem as overwhelming as global climate change. Even when people believe that climate change presents a dire threat and they acknowledge that behavior change by a large part of the world's population would help, they may believe changing their personal behavior is futile (McGrath 2020): that "individual voluntary behaviors in and of themselves to have no bearing on the macro political problem of climate change, which requires global coordination, not personal commitments" (see also Bubeck et al. 2012; Hornsey et al. 2016; Kellstedt et al. 2008).

On the basis of this literature, we pose the following research question (research question 1): Do messages that recommend personal behavior change or collective policies to combat climate change affect individuals' (i) willingness to take personal steps or support collective actions to address climate change, (ii) support for political candidates with a proclimate agenda, and (iii) belief in human-caused climate change?

\section{b. Message source effects}

A long and robust history of empirical research on communication and environmental risk perceptions makes clear that the messages are more impactful when they emanate from credible and trustworthy sources (Brewer and Ley 2013; Druckman 2001; Lupia 2013; Benegal and Scruggs 2018; Bolsen et al. 2019; Van Boven et al. 2018). The question this research poses is whether attribution to an unnamed climate scientist makes the message more or less credible and trustworthy, or, alternatively, if such attribution does not affect the impact of the message.

Linking recommendations for individual and collective action on climate change to expert scientists might influence positive response because of the high level of overall trust that Americans report for the scientific community compared with 
TABLE 1. Experimental design and treatments.

\begin{tabular}{|c|c|}
\hline Condition & Treatment \\
\hline No source frame (baseline) $(N=319)$ & $\begin{array}{l}\text { Climate change is a threat to both the environment and the national security of the } \\
\text { United States }\end{array}$ \\
\hline No source + individual action $(N=319)$ & $\begin{array}{l}\text { Climate change is a threat to both the environment and the national security of the } \\
\text { United States; it is recommended that we as individuals } \\
\text { take fewer plane flights } \\
\text { drive less } \\
\text { eat less beef } \\
\text { use less hot water } \\
\text { adjust the thermostat }\end{array}$ \\
\hline No source + policy action $(N=317)$ & $\begin{array}{l}\text { Climate change is a threat to both the environment and the national security of the } \\
\text { United States; it is recommended that we as a nation adopt new laws that } \\
\text { limit the amount of carbon pollution in the air } \\
\text { stop deforestation } \\
\text { require business and industry shift from coal to sustainable energy } \\
\text { increase vehicle fuel efficiency } \\
\text { retrofit all public buildings to make them maximally energy efficient }\end{array}$ \\
\hline Climate scientist $(N=319)$ & $\begin{array}{l}\text { Climate scientists say that climate change is a threat to both the environment and the } \\
\text { national security of the United States }\end{array}$ \\
\hline Climate scientist + individual action $(N=319)$ & $\begin{array}{l}\text { Climate scientists say that climate change is a threat to both the environment and the } \\
\text { national security of the United States; they recommend that we as individuals } \\
\text { take fewer plane flights } \\
\text { drive less } \\
\text { eat less beef } \\
\text { use less hot water } \\
\text { adjust the thermostat }\end{array}$ \\
\hline Climate scientist + policy action $(N=319)$ & $\begin{array}{l}\text { Climate scientists say that climate change is a threat to both the environment and the } \\
\text { national security of the United States; they recommend that we as a nation adopt } \\
\text { new laws that } \\
\text { limit the amount of carbon pollution in the air } \\
\text { stop deforestation } \\
\text { require business and industry shift from coal to sustainable energy } \\
\text { increase vehicle fuel efficiency } \\
\text { retrofit all public buildings to make them maximally energy efficient }\end{array}$ \\
\hline
\end{tabular}

other institutions (Krause et al. 2019; Mullin 2017). In this scenario, trust in the scientific community should translate to trust in climate scientists when they discuss issues in their area of expertise including climate change.

Alternatively, however, empirical studies have shown that this general trust in science or in scientists is not universal within the United States. Instead, numerous surveys have found an association between conservative political ideology and a loss of trust both in science itself as well as in scientists (Hamilton et al. 2015; Krause et al. 2019; Leiserowitz et al. 2012; McCright et al. 2013; Safford et al. 2019). This distrust is exacerbated when scientists themselves engage in public policy debates (Brulle 2018; Milkoreit et al. 2015; Motta 2018). The tendency of political polarization around scientifically based warnings has been documented most recently with respect to the COVID-19 pandemic (Ballew et al. 2020; Ellis 2020; Krause et al. 2019; Pennycook et al. 2020; Van Bavel et al. 2020).

In a recent study, we compared the impact of climate scientists with party leaders and military leaders, and found that climate scientists had relatively little positive impact on the perceived threat of climate change when the message was linked with a mild suggestion to "promote energy efficiency and renewable energy technologies" (Bolsen et al. 2019). We found that when information about the national security or environmental effects of climate change was attributed to climate scientists, this linkage often weakened the impact of the message for Republicans and Independents. In the current study, we focused on the combination of specific packages of recommendations attributed either to a climate scientist or with no attribution to elucidate the influence of message type and message source.

On the basis of this literature, we pose the following research question (research question 2): When a message that recommends specific individual or collective actions to combat climate change is attributed to an unnamed "climate scientist," does this attribution have an effect on the message's impact or on the degree to which there is general trust in climate scientists to provide unbiased and impartial information?

\section{Methods}

We administered a survey over the period of 23 September1 October 2019 using Amazon's Mechanical Turk to recruit 
TABLE 2. Personal action: main effects. Cell entries are OLS coefficients with standard errors, with two-tailed $p$ values presented in the adjacent column. Coefficients represent the estimated difference in means between the treatment condition and the no-source baseline condition. A single asterisk indicates $p<0.05$, and a double asterisk indicates $p<0.01$. AIC and BIC are the Akaike information criterion and Bayesian information criterion, respectively.

\begin{tabular}{|c|c|c|c|c|c|c|c|c|}
\hline & \multicolumn{2}{|c|}{ All } & \multicolumn{2}{|c|}{ Republican } & \multicolumn{2}{|c|}{ Independent } & \multicolumn{2}{|c|}{ Democrat } \\
\hline & Coef & $p$ value & Coef & $p$ value & Coef & $p$ value & Coef & $p$ value \\
\hline NS individual action & $-0.31^{*}(0.12)$ & 0.013 & $-0.51(0.27)$ & 0.059 & $-0.41(0.23)$ & 0.078 & $0.05(0.13)$ & 0.684 \\
\hline NS policy action & $-0.11(0.12)$ & 0.362 & $-0.11(0.28)$ & 0.685 & $-0.16(0.24)$ & 0.505 & $-0.09(0.13)$ & 0.491 \\
\hline CS source & $-0.14(0.12)$ & 0.254 & $-0.40(0.28)$ & 0.148 & $0.03(0.23)$ & 0.902 & $-0.08(0.13)$ & 0.548 \\
\hline CS individual action & $-0.23(0.12)$ & 0.066 & $-0.40(0.27)$ & 0.137 & $-0.23(0.24)$ & 0.331 & $-0.04(0.13)$ & 0.739 \\
\hline CS policy action & $-0.13(0.12)$ & 0.299 & $-0.12(0.28)$ & 0.681 & $-0.46(0.24)$ & 0.053 & $0.07(0.13)$ & 0.597 \\
\hline Constant (no source) & $5.58 * *(0.09)$ & 0.000 & $4.96 * *(0.20)$ & 0.000 & $5.47 * *(0.17)$ & 0.000 & $5.99 * *(0.09)$ & 0.000 \\
\hline$N$ & 1906 & & 505 & & 551 & & 850 & \\
\hline AIC & 7071.0 & & 2020.0 & & 2074.4 & & 2583.7 & \\
\hline $\mathrm{BIC}$ & 7104.4 & & 2045.3 & & 2100.3 & & 2612.2 & \\
\hline
\end{tabular}

1915 unique respondents. ${ }^{1}$ Following a brief introduction, respondents opting to participate were randomly assigned to one of six experimental conditions (see Table 1). These included 1) a simple sentence stating that "climate change is a threat to both the environment and the national security of the United States" (no source baseline); 2) the same sentence attributed to climate scientists (climate scientists source); 3) the no-source baseline sentence with an added statement that "it is recommended that we as individuals take fewer plane flights, drive less, eat less beef, use less hot water and adjust the thermostat" (no source + individual actions); 4) the baseline sentence with individual behavioral recommendations attributed to climate scientists (climate scientists + individual actions); 5) the nosource baseline sentence with the statement that "it is recommended that we as a nation adopt new laws that: limit the amount of carbon pollution in the air, stop deforestation, require business and industry to switch from coal to sustainable energy, increase vehicle fuel efficiency, and retrofit all public buildings to make them maximally energy efficient" (no source + policy actions), and 6) the baseline sentence along with the same policy recommendations attributed to a climate scientist (climate scientists + policy actions). The experimental design was constructed to vary two dimensions: the extent to which the statement was accompanied by recommendations concerning personal behavior or policy changes, and whether or not the statement was attributed to a climate scientist or no source.

\section{Dependent variables}

We measured how exposure to the experimental treatments affected respondent beliefs on four key outcome measures.

\footnotetext{
${ }^{1}$ MTurk is a widely used online crowdsourcing platform, producing a convenience sample that differs from the general population but not in ways that impede making generalizable causal inferences (Levay et al. 2016; Clifford et al. 2015). Further, the results have been found to be comparable to identical studies fielded on general population samples (Mullinix et al. 2015). Sample demographics are included in Table A1 in the appendix. We restricted the survey to individuals who had completed a minimum of 200 previous tasks on MTurk with a minimum approval rate of $95 \%$.
}

After respondents had read the headline or short paragraph, they were asked, "How willing are you to take steps in your own life that would reduce greenhouse gas emissions as a way to fight climate change?" on a 7-point response scale $(1=$ strongly unwilling; $7=$ strongly willing $)$. The second question was, "How willing are you to vote for candidates who favor greater regulation of carbon emissions by business and industry, and higher taxes on carbon emitters?" on a 7-point response scale $(1=$ strongly disagree; $7=$ strongly agree $)$. Third, respondents were asked the extent to which they agreed or disagreed with the statement, "Climate change is occurring faster now because of human activity" on a 7-point response scale $(1=$ strongly disagree $; 7=$ strongly agree $)$. Last, they were asked, "How much would you say that you trust climate scientists to provide accurate and impartial information?" $(1=$ strongly distrust; $7=$ strongly trust). Since so much of the previous survey research has found robust effects of political party identification with their response to climate information, we also analyzed the impacts of political partisanship.

\section{Results}

To test our research questions, we estimated a series of ordinary least squares (OLS) regression models. In each model we omit the no-source baseline condition as our reference group and regress the dependent variable on the condition indicators. For each dependent variable, we first report the full main effects model using all respondents in the sample. Following this, we present a series of subset models restricting the analysis to 1) Republicans, 2) Independents, and 3) Democrats in the sample. In all models, cell entries contain OLS coefficients representing the difference in means between the treatment condition and the no-source baseline condition. Standard errors are presented in parentheses below, and two-tailed $p$ values are reported alongside the coefficient estimates. ${ }^{2}$

\footnotetext{
${ }^{2}$ Additional analyses, including sample demographics and the results of a balance test, are available in the appendix. A comprehensive test of source effects is also presented in the appendix.
} 
TABLE 3. Vote for candidates: main effects. Cell entries are OLS coefficients with standard errors in parentheses. Two-tailed $p$ values are presented in the adjacent column. Coefficients represent the estimated difference in means between the treatment condition and the no-source baseline condition. A single asterisk indicates $p<0.05$, and a double asterisk indicates $p<0.01$.

\begin{tabular}{|c|c|c|c|c|c|c|c|c|}
\hline & \multicolumn{2}{|l|}{ All } & \multicolumn{2}{|c|}{ Republican } & \multicolumn{2}{|c|}{ Independent } & \multicolumn{2}{|c|}{ Democrat } \\
\hline & Coef & $p$ value & Coef & $p$ value & Coef & $p$ value & Coef & $p$ value \\
\hline NS individual action & $-0.42 * *(0.14)$ & 0.003 & $-0.51^{*}(0.29)$ & 0.077 & $-0.53 *(0.26)$ & 0.041 & $-0.05(0.14)$ & 0.695 \\
\hline NS policy action & $-0.26(0.14)$ & 0.070 & $0.02(0.29)$ & 0.944 & $-0.65 *(0.27)$ & 0.015 & $-0.20(0.13)$ & 0.142 \\
\hline CS source & $-0.26(0.14)$ & 0.067 & $-0.27(0.29)$ & 0.360 & $-0.42(0.26)$ & 0.108 & $-0.11(0.13)$ & 0.396 \\
\hline CS individual action & $-0.51 * *(0.14)$ & 0.000 & $-0.47(0.28)$ & 0.099 & $-0.94 * *(0.27)$ & 0.001 & $-0.13(0.14)$ & 0.324 \\
\hline CS policy action & $-0.18(0.14)$ & 0.222 & $-0.20(0.30)$ & 0.493 & $-0.76 * *(0.27)$ & 0.004 & $0.19(0.13)$ & 0.150 \\
\hline Constant (no source) & $5.54 * *(0.10)$ & 0.000 & $4.33 * *(0.21)$ & 0.000 & $5.39 * *(0.19)$ & 0.000 & $6.29 * *(0.09)$ & 0.000 \\
\hline$N$ & 1911 & & 507 & & 552 & & 852 & \\
\hline AIC & 7705.7 & & 2081.2 & & 2215.4 & & 2656.7 & \\
\hline $\mathrm{BIC}$ & 7739.0 & & 2106.6 & & 2241.3 & & 2685.2 & \\
\hline
\end{tabular}

\section{a. Personal action}

The first effect that we analyzed was willingness to take personal action as indicated by response to the question, "How willing are you to take steps in your own life that would reduce greenhouse gas emissions as a way to fight climate change? Changes might include driving conventional cars alone less, conserving energy in your home, or changing your diet." As shown in Table 2, when "no source" was linked with suggestions for making behavioral changes (NS individual action), the effect was to reduce willingness to take action $(b=-0.31$, with $p=0.01)$; in other words, the difference in the mean score of those exposed to this treatment as compared with the baseline group was one-third of a point on the 7-point scale. None of the other conditions elicited a statistically significant effect at conventional levels in the full model. Further, in our analyses of partisan groups, no estimates reach statistical significance at $p<0.05$.

\section{b. Preference for political candidates that support climate mitigation}

We next analyzed the responses to the question, "How willing are you to vote for candidates who favor greater regulation of carbon emissions by business and industry, and higher taxes on carbon emitters?" Note that this question does not ask for changes in personal behavior and is a classic "upstream" delegation of responsibility. Shown in Table 3, when the treatment was linked with individual behavioral change and came either from no source (NS individual action) or an unnamed climate scientist (CS individual action), the response was negative: the respondents were significantly less likely (NS individual action: $b=-0.42$, with $p=0.003$; CS individual action: $b=-0.51$, with $p=0.00$ ) than the no-source baseline group to respond that they would vote for a candidate that supports climate mitigation. There were similar negative effects for both the general climate scientists' source $(b=-0.26$, with $p=0.06)$ and the no-source policy action conditions (NS policy action: $b=-0.26$, with $p=0.07$ ).

Across the party groups, only the Independents showed treatment effects across a broader range of conditions: when individual action or policy changes were suggested either by no source or by a climate scientist, Independents stated that they were significantly less likely to vote for candidates supporting climate legislation than their copartisans in the baseline. For Independents, the only condition that did not elicit a statistically significant response was the addition of a climate scientist source (CS source) to the baseline statement.

\section{c. Accelerated anthropogenic climate change}

The treatments did not specifically address the issue of the accelerating pace of climate change due to human activity but the responses to this question did vary in different message

TABLE 4. Climate change is occurring faster: main effects. Cell entries are OLS coefficients with standard errors in parentheses. Twotailed $p$ values are presented in the adjacent column. Coefficients represent the estimated difference in means between the treatment condition and the no-source baseline condition. A single asterisk indicates $p<0.05$, and a double asterisk indicates $p<0.01$.

\begin{tabular}{|c|c|c|c|c|c|c|c|c|}
\hline & \multicolumn{2}{|l|}{ All } & \multicolumn{2}{|c|}{ Republican } & \multicolumn{2}{|c|}{ Independent } & \multicolumn{2}{|c|}{ Democrat } \\
\hline & Coef & $p$ value & Coef & $p$ value & Coef & $p$ value & Coef & $p$ value \\
\hline NS individual action & $-0.34 *(0.13)$ & 0.011 & $-0.53(0.29)$ & 0.072 & $-0.35(0.24)$ & 0.146 & $-0.01(0.12)$ & 0.915 \\
\hline NS policy action & $-0.12(0.13)$ & 0.355 & $0.13(0.30)$ & 0.670 & $-0.41(0.25)$ & 0.099 & $-0.11(0.11)$ & 0.338 \\
\hline CS source & $-0.19(0.13)$ & 0.155 & $-0.39(0.30)$ & 0.193 & $-0.03(0.24)$ & 0.889 & $-0.15(0.12)$ & 0.190 \\
\hline CS individual action & $-0.38 * *(0.13)$ & 0.005 & $-0.40(0.29)$ & 0.170 & $-0.71 * *(0.25)$ & 0.005 & $-0.03(0.12)$ & 0.768 \\
\hline CS policy action & $-0.19(0.13)$ & 0.162 & $-0.27(0.30)$ & 0.378 & $-0.64 * *(0.25)$ & 0.009 & $0.13(0.12)$ & 0.277 \\
\hline Constant (no source) & $5.76 * *(0.09)$ & 0.000 & $4.65 * *(0.21)$ & 0.000 & $5.71 * *(0.18)$ & 0.000 & $6.40 * *(0.08)$ & 0.000 \\
\hline$N$ & 1912 & & 507 & & 552 & & 853 & \\
\hline AIC & 7452.7 & & 2104.9 & & 2131.2 & & 2407.0 & \\
\hline $\mathrm{BIC}$ & 7486.0 & & 2130.2 & & 2157.1 & & 2435.4 & \\
\hline
\end{tabular}


TABLE 5. Trust climate scientists: main effects. Cell entries are OLS coefficients with standard errors in parentheses. Two-tailed $p$ values are presented in the adjacent column. Coefficients represent the estimated difference in means between the treatment condition and the no-source baseline condition. A single asterisk indicates $p<0.05$, and a double asterisk indicates $p<0.01$.

\begin{tabular}{|c|c|c|c|c|c|c|c|c|}
\hline & \multicolumn{2}{|l|}{ All } & \multicolumn{2}{|c|}{ Republican } & \multicolumn{2}{|c|}{ Independent } & \multicolumn{2}{|c|}{ Democrat } \\
\hline & Coef & $p$ value & Coef & $p$ value & Coef & $p$ value & Coef & $p$ value \\
\hline NS individual action & $-0.34 *(0.14)$ & 0.011 & $-0.58 *(0.29)$ & 0.043 & $-0.36(0.25)$ & 0.143 & $0.03(0.12)$ & 0.771 \\
\hline NS policy action & $-0.15(0.14)$ & 0.276 & $-0.10(0.30)$ & 0.737 & $-0.47(0.26)$ & 0.066 & $-0.00(0.11)$ & 0.990 \\
\hline CS source & $-0.07(0.14)$ & 0.586 & $-0.17(0.29)$ & 0.561 & $-0.06(0.25)$ & 0.806 & $0.02(0.12)$ & 0.880 \\
\hline CS individual action & $-0.37 * *(0.14)$ & 0.006 & $-0.62 * *(0.28)$ & 0.029 & $-0.59 *(0.26)$ & 0.022 & $0.05(0.12)$ & 0.681 \\
\hline CS policy action & $-0.03(0.14)$ & 0.826 & $-0.07(0.30)$ & 0.818 & $-0.43(0.25)$ & 0.088 & $0.23 *(0.11)$ & 0.042 \\
\hline Constant (no source) & $5.53 * *(0.10)$ & 0.000 & $4.54 * *(0.21)$ & 0.000 & $5.31 * *(0.18)$ & 0.000 & $6.21 * *(0.08)$ & 0.000 \\
\hline$N$ & 1909 & & 506 & & 551 & & 852 & \\
\hline AIC & 7476.3 & & 2080.4 & & 2160.5 & & 2395.4 & \\
\hline $\mathrm{BIC}$ & 7509.6 & & 2105.8 & & 2186.4 & & 2423.9 & \\
\hline
\end{tabular}

formats (Table 4). Overall, when asked, "To what extent do you disagree or agree that "climate change is occurring faster now because of human activity,', respondents were less likely to attest that the climate is changing faster because of human activity when this message was linked with changes in personal behavior either attributed to no source (NS individual action: $b=-0.34$, with $p=0.01$ ) or to a climate scientist (CS individual action: $b=-0.38$, with $p=0.00)$. When linked with policy recommendations (NS policy action and CS policy action) or no recommendations at all (CS source), there was no impact on the response.

Across partisan groups, none of the treatments had a significant impact on responses for Democrats or Republicans. However, among Independents, the treatment condition did affect response: when the message was linked with climate scientists and either mentioned individual $(b=-0.71$, with $p<0.01)$ or policy changes $(b=-0.64$, with $p<0.01)$, Independents were significantly less likely to respond that climate change is accelerating as a result of human action.

\section{d. Trust climate scientists to provide accurate information}

Our final set of analyses examines the effects of the treatments on answers to "How much would you say that you trust climate scientists to provide accurate and impartial information?" (Table 5). Overall, this message linked with suggestions for changes in individual behavior reduced trust in climate scientists both when no source $(b=-0.34$, with $p=0.01)$ was mentioned or when a climate scientist $(b=-0.37$, with $p<0.01)$ was mentioned. The policy recommendations had no effect overall on response. Among partisans, Republicans were less likely to state that they trust climate scientists when the message was linked with suggestions for change in personal behavior $(b=-0.58$, with $p=0.04)$, and both Republicans $(b=-0.62$, with $p=0.02)$ and Independents $(b=-0.59$, with $p=0.02)$ were less likely to trust climate scientists when climate scientists recommended changes in personal behavior. Among Democrats, those exposed to policy recommendations accompanied by a climate scientist source had higher scores for trust in climate scientist $(b=0.23$, with $p=0.04)$, while there was no impact from the remaining conditions.

\section{Discussion}

This study evaluates the impact of messages suggesting the need for changes in individual behavior or public policy attributed to no source or to an unnamed climate scientist. We found that when messages advocate "solutions" to combat climate change that would require major changes in individual behavior, the general response was less willingness to support

TABLE A1. Descriptive statistics.

\begin{tabular}{|c|c|c|}
\hline Variable & Value & $N(\%)$ \\
\hline \multirow[t]{7}{*}{ Age } & $18-24$ & $199(10.4 \%)$ \\
\hline & $25-34$ & $697(36.5 \%)$ \\
\hline & $35-44$ & $488(25.5 \%)$ \\
\hline & $45-54$ & $284(14.9 \%)$ \\
\hline & $55-64$ & $171(8.9 \%)$ \\
\hline & $65-74$ & $68(3.6 \%)$ \\
\hline & 75 or older & $5(0.2 \%)$ \\
\hline \multirow[t]{2}{*}{ Female } & Male & $681(35.9 \%)$ \\
\hline & Female & $1217(64.1 \%)$ \\
\hline \multirow[t]{5}{*}{ Race } & White & $1409(73.7 \%)$ \\
\hline & African American & $195(10.2 \%)$ \\
\hline & Asian American & $136(7.1 \%)$ \\
\hline & Hispanic & $103(5.4 \%)$ \\
\hline & Mixed race or other & $69(3.6 \%)$ \\
\hline \multirow[t]{7}{*}{ Education } & Less than high school & $14(0.7 \%)$ \\
\hline & High school graduate & $179(9.4 \%)$ \\
\hline & Some college & $428(22.4 \%)$ \\
\hline & 2-yr degree & $240(12.6 \%)$ \\
\hline & 4-yr degree & $741(38.8 \%)$ \\
\hline & Professional degree & $275(14.4 \%)$ \\
\hline & Doctorate & $35(1.8 \%)$ \\
\hline \multirow[t]{9}{*}{ Income } & Less than $\$ 15,000$ & $142(7.4 \%)$ \\
\hline & $\$ 15,000-\$ 24,999$ & $190(9.9 \%)$ \\
\hline & $\$ 25,000-\$ 34,999$ & $219(11.5 \%)$ \\
\hline & $\$ 35,000-\$ 49,999$ & $301(15.7 \%)$ \\
\hline & $\$ 50,000-\$ 74,999$ & $420(22.0 \%)$ \\
\hline & $\$ 75,000-\$ 99,999$ & $292(15.3 \%)$ \\
\hline & $\$ 100,000-\$ 149,999$ & $259(13.5 \%)$ \\
\hline & $\$ 150,000-\$ 199,999$ & $51(2.7 \%)$ \\
\hline & More than $\$ 200,000$ & $38(2.0 \%)$ \\
\hline \multirow[t]{3}{*}{ Political party } & Republican & $507(26.5 \%)$ \\
\hline & Independent & $552(28.9 \%)$ \\
\hline & Democrat & $853(44.6 \%)$ \\
\hline \multirow[t]{3}{*}{ Ideology } & Conservative & $557(29.1 \%)$ \\
\hline & Moderate & $503(26.3 \%)$ \\
\hline & Liberal & $852(44.6 \%)$ \\
\hline
\end{tabular}


TABLE A2. Balance test. Cell entries are logit coefficients with standard errors in parentheses. A single asterisk indicates $p<0.05$, and a double asterisk indicates $p<0.01$.

\begin{tabular}{lcccrrr}
\hline \hline & No source & NS individual action & NS policy action & CS source & CS individual action & CS policy action \\
\hline Female & $0.08(0.13)$ & $-0.07(0.13)$ & $-0.15(0.13)$ & $-0.09(0.13)$ & $0.16(0.13)$ & $0.08(0.13)$ \\
Minority & $-0.13(0.15)$ & $0.07(0.14)$ & $0.06(0.14)$ & $0.13(0.14)$ & $-0.10(0.15)$ & $-0.05(0.14)$ \\
Republican & $-0.01(0.17)$ & $-0.01(0.16)$ & $0.05(0.17)$ & $-0.10(0.17)$ & $0.14(0.17)$ & $-0.07(0.17)$ \\
Democrat & $0.10(0.15)$ & $-0.21(0.15)$ & $0.11(0.15)$ & $-0.07(0.15)$ & $0.06(0.15)$ & $0.01(0.15)$ \\
Age & $-0.02(0.05)$ & $0.04(0.05)$ & $-0.07(0.05)$ & $0.04(0.05)$ & $0.04(0.05)$ & $-0.03(0.05)$ \\
Education & $-0.04(0.05)$ & $-0.02(0.05)$ & $0.05(0.05)$ & $0.03(0.05)$ & $-0.04(0.05)$ & $0.02(0.05)$ \\
Income & $0.01(0.03)$ & $-0.02(0.03)$ & $-0.03(0.03)$ & $0.04(0.03)$ & $0.04(0.03)$ & $-0.04(0.03)$ \\
Constant & $-1.50 *(0.31)$ & $-1.47 *(0.30)$ & $-1.38^{* *}(0.31)$ & $-1.96 * *(0.31)$ & $-1.93 * *(0.31)$ & $-1.44 *(0.31)$ \\
$N$ & 1898 & 1898 & 1898 & 1898 & 1898 & 1898 \\
\hline
\end{tabular}

promitigation candidates, a reduced belief in human-induced climate change, and, in the case of this message delivered by "no source," less willingness to take personal actions to reduce emissions. In addition, messages recommending individual behavior changes as a way to address climate change, with or without the subtle source attribution linking the recommendation to a climate scientist, reduced trust in climate scientists to provide accurate and impartial information. Messages that imply the need for individual sacrifices in living style that will be required to reduce emissions are thus translated into a negative response to the entire message, including an increased skepticism about climate science and trust in climate scientists. Messages about policies that would affect others, such as taxes on industry and business or on carbon emitters, are more palatable and do not result in such a negative response.

Response to the messages was strongly influenced by the political identification of the respondents. In general, support for various actions and proclimate beliefs was stronger among Democrats than among Republicans in the no-source baseline condition. Further, Republicans and Independents tended to respond more negatively in certain conditions if the message was attributed to a climate scientist. This finding links back to the increasingly large set of findings that have demonstrated conservative skepticism about a variety of scientific messages, but the fact that the Independents reacted so negatively to these messages in our study warrants further investigation. Our small sample size permits only conjecture about the ways in which Independents are responding, but the finding warrants study with a larger and more representative sample.

Given the nature of our sample, we are cautious about the generalizability of our findings, and we encourage future work on representative samples to probe additional factors that may condition the impact of a wider range of individual behaviors and policy recommendations targeting climate mitigation efforts. Future research should identify the specific actions or policies that will be palatable to particular groups of listeners so that the entire process does not backfire. We acknowledge that respondents may have been reacting negatively to portions of the message seeking individual action (e.g., changes in diet). Future research should unpack the reactions to specific behavioral suggestions in order to tailor effective messages for diverse populations (Nielsen et al. 2020a). Respondents might also not connect recommended behavioral changes to actual reductions in global concentrations of carbon dioxide, and the framing of this connection needs to be explored (van der Linden 2016). In addition, future work needs to extend our understanding of source effects, particularly those with ascribed scientific expertise.

\section{APPENDIX}

\section{Sample Demographics and Supplementary Analyses}

Table A1 presents sample demographics, illustrated through the descriptive statistics, given as the number $N$ in the sample for each demographic category and the associated percentage. The results of a balance test are presented in Table A2.

Table A3 provides a comprehensive test of climate scientist source effects. An additional set of analyses was done to examine whether, and to what degree, there is evidence of source effects, that is, the difference between a message attributed to a climate scientist as opposed to no identified source. We perform a series of $t$ tests between the "no source" (NS) and "climate scientist source" (CS) while holding constant the message content. If the climate scientist as a source of

TABLE A3. Climate scientist source effect. Cell entries are coefficient estimates with standard errors in parentheses.

\begin{tabular}{|c|c|c|c|c|c|c|}
\hline & \multicolumn{2}{|c|}{ NS vs CS source } & \multicolumn{2}{|c|}{$\begin{array}{c}\text { NS individual vs CS } \\
\text { individual }\end{array}$} & \multicolumn{2}{|c|}{ NS policy vs CS policy } \\
\hline & Diff & $p$ value & Diff & $p$ value & Diff & $p$ value \\
\hline Trust climate scientists & $0.07(0.125)$ & 0.557 & $0.03(0.144)$ & 0.858 & $-0.12(0.137)$ & 0.39 \\
\hline Vote for candidates & $0.26(0.136)$ & 0.053 & $0.08(0.15)$ & 0.572 & $-0.09(0.145)$ & 0.558 \\
\hline Personal action & $0.14(0.117)$ & 0.233 & $-0.08(0.129)$ & 0.535 & $0.02(0.122)$ & 0.9 \\
\hline Climate change occurring faster & $0.19(0.128)$ & 0.137 & $0.03(0.139)$ & 0.804 & $0.06(0.136)$ & 0.64 \\
\hline
\end{tabular}


information were having a separate and meaningful effect, we would expect systematic significant differences in the means across the dependent variables. The results indicate that in all but one test there is no statistically significant difference between the NS and CS (Table A3). This finding corroborates and extends the conclusions from our prior work (Bolsen et al. 2019) in that there is no impact of climate scientists as a message source independent of the message's content, but it also extends this finding to show no impact of climate scientists as an information source across a variety of potential mitigation measures.

\section{REFERENCES}

Attari, S. Z., M. L. DeKay, C. I. Davidson, and W. B. de Bruin, 2011: Changing household behaviors to curb climate change: How hard can it be? Sustainability, 4, 9-11, https://doi.org/ 10.1089/SUS.2010.9724.

Ballew, M., and Coauthors, 2020: American Public Responses to COVID-19, April 2020. Yale Program on Climate Change Communication Doc., 203 pp., https://climatecommunication.yale.edu/ wp-content/uploads/2020/04/american-public-responses-covid19april-2020b.pdf.

Benegal, S. D., and L. A. Scruggs, 2018: Correcting misinformation about climate change: The impact of partisanship in an experimental setting. Climatic Change, 148, 61-80, https:// doi.org/10.1007/s10584-018-2192-4.

Bolsen, T., 2013: A light bulb goes on: Norms, rhetoric, and actions for the public good. Polit. Behav., 35, 1-20, https://doi.org/ 10.1007/s11109-011-9186-5.

—_, and M. A. Shapiro, 2017: Strategic framing and persuasive messaging to influence climate change perceptions and decisions. Oxford Research Encyclopedia of Climate Science, H. Von Storch et al., Eds., Oxford University Press, https:// doi.org/10.1093/acrefore/9780190228620.013.385.

_ _ J. N. Druckman, and F. L. Cook, 2014a: Communication and collective actions: A survey experiment on motivating energy conservation in the US. J. Exp. Polit. Sci., 1, 24-38, https:// doi.org/10.1017/xps.2014.2.

__ T. J. Leeper, and M. A. Shapiro, 2014b: Doing what others do: Norms, science, and collective action on global warming. Amer. Polit. Res., 42, 65-89, https://doi.org/10.1177/ $1532673 X 13484173$.

— R. I. Palm, and J. T. Kingsland, 2019: The impact of message source on effectiveness of communications about climate change. Sci. Commun., 41, 464-487, https://doi.org/10.1177/ 1075547019863154.

Bord, R. J., A. Fisher, and E. O. Robert, 1998: Public perceptions of global warming: United States and international perspectives. Climate Res., 11, 75-84, https://doi.org/10.3354/cr011075.

Bostrom, A., M. G. Morgan, B. Fischhoff, and D. Read, 1994: What do people know about global climate change? Mental models. Risk Anal., 14, 959-970, https://doi.org/10.1111/ j.1539-6924.1994.tb00065.x.

Brewer, P. R., and B. L. Ley, 2013: Whose science do you believe? Explaining trust in sources of scientific information about the environment. Sci. Commun., 35, 115-137, https://doi.org/ 10.1177/1075547012441691.

Brulle, R. J., 2018: Critical reflections on the March for Science. Sociol. Forum, 33, 255-258, https://doi.org/10.1111/SOCF.12398.

Bubeck, P., W. J. W. Botzen, and J. C. J. H. Aerts, 2012: A review of risk perceptions and other factors that influence flood mitigation behavior Risk Anal., 32, 1481-1495, https://doi.org/ 10.1111/j.1539-6924.2011.01783.x.
Buntaine, M.T. and Prather, L., 2018: Preferences for domestic action over international transfers in global climate policy. J. Exp. Pol. Sci., 5, 73-87, https://doi.org/10.1017/XPS.2017.34.

Campbell, T. H., and A. C. Kay, 2014: Solution aversion: On the relation between ideology and motivated disbelief. J. Pers. Soc. Psychol., 107, 809-824, https://doi.org/10.1037/a0037963.

Campbell, W. K., and C. Sedikides, 1999: Self-threat magnifies the self-serving bias: A meta-analytic integration. Rev. Gen. Psychol., 3, 23-43, https://doi.org/10.1037/1089-2680.3.1.23.

Capstick, S., I. Lorenzoni, A. Corner, and L. Whitmarsh, 2014: Prospects for radical emissions reduction through behavior and lifestyle change. Carbon Manage., 5, 429-445, https:// doi.org/10.1080/17583004.2015.1020011.

Chong, D., and J. N. Druckman, 2007: Framing theory. Annu. Rev. Polit. Sci., 10, 103-126, https://doi.org/10.1146/ annurev.polisci.10.072805.103054.

Clifford, S., R. M. Jewell, and P. D. Waggoner, 2015: Are samples drawn from Mechanical Turk valid for research on political ideology? Res. Polit., 2, 1-9, https://doi.org/10.1177/2053168015622072.

De Boer, J., H. Schösler, and J. J. Boersema, 2013: Climate change and meat eating: An inconvenient couple? J. Environ. Psychol., 33, 1-8, https://doi.org/10.1016/j.jenvp.2012.09.001.

Dietz, T., G. T. Gardner, J. Gilligan, P. C. Stern, and M. P. Vandenbergh, 2009: Household actions can provide a behavioral wedge to rapidly reduce US carbon emissions. Proc. Natl. Acad. Sci. USA, 106, 18 452-18 456, https://doi.org/10.1073/pnas.0908738106.

Druckman, J. N., 2001: Using credible advice to overcome framing effects. J. Law Econ. Organ., 17, 62-82, https://doi.org/ 10.1093/jleo/17.1.62.

_ 2011: What's it all about? Perspectives on Framing, G. Keren, Ed., Psychology Press/Taylor and Francis, 279-302. , 2015: Communicating policy-relevant science. PS Polit. Sci. Polit., 48, 58-69, https://doi.org/10.1017/S1049096515000438. , and M. C. McGrath, 2019: The evidence for motivated reasoning in climate change preference formation. Nat. Climate Change, 9, 111-119, https://doi.org/10.1038/s41558-018-0360-1.

Ellis, E. G., 2020: The coronavirus outbreak is a petri dish for conspiracy theories. Wired, 4 February, https://www.wired.com/ story/coronavirus-conspiracy-theories/.

Fujiwara, J., N. Nobuo, S. Q. Park, T. Williams, T. Iijima, M. Taira, K.-I. Tsutsui, and P. N. Tobler, 2013: Value of freedom to choose encoded by the human brain. J. Neurophysiol., 110, 1915-1929, https://doi.org/10.1152/jn.01057.2012.

Gifford, R., 2011: The dragons of inaction: Psychological barriers that limit climate change mitigation and adaptation. Amer. Psychol., 66, 290-302, https://doi.org/10.1037/a0023566.

_ C. Kormos, and A. McIntyre, 2011: Behavioral dimensions of climate change: Drivers, responses, barriers, and interventions. Wiley Interdiscip. Rev.: Climate Change, 2, 801-827, https://doi.org/10.1002/wcc.143.

Green, R., J. Milner, A. D. Dangour, A. Haines, Z. Chalabi, A. Markandya, J. Spadaro, and P. Wilkinson, 2015: The potential to reduce greenhouse gas emissions in the UK through healthy and realistic dietary change. Climatic Change, 129, 253-265, https://doi.org/10.1007/s10584-015-1329-y.

Hamilton, L. C., J. Hartter, and K. Saito, 2015: Trust in scientists on climate change and vaccines. SAGE Open, 5, 1-13, https:// doi.org/10.1177/2158244015602752.

Hardisty, D. J., A. T. Beall, R. Lubowski, A. Petsonk, and R. Romero-Canyas, 2019: A carbon price by another name may seem sweeter: Consumers prefer upstream offsets to downstream taxes. J. Environ. Psychol., 66, 101342, https:// doi.org/10.1016/j.jenvp.2019.101342. 
Hart, P. S., and L. Feldman, 2016: The impact of climate change-related imagery and text on public opinion and behavior change. Sci. Commun., 38, 415-441, https://doi.org/10.1177/1075547016655357.

Hmielowski, J. D., L. Feldman, T. A. Myers, A. Leiserowitz, and E. Maibach, 2014: An attack on science? Media use, trust in scientists, and perceptions of global warming. Public Understanding Sci., 23, 866-883, https://doi.org/10.1177/0963662513480091.

Hornsey, M. J., E. A. Harris, P. G. Bain, and K. S. Fielding, 2016: Meta-analyses of the determinants and outcomes of belief in climate change. Nat. Climate Change, 6, 622-626, https:// doi.org/10.1038/nclimate2943.

Kellstedt, P. M., S. Zahran, and A. Vedlitz, 2008: Personal efficacy, the information environment, and attitudes toward global warming and climate change in the United States. Risk Anal., 28, 113-126, https://doi.org/10.1111/j.1539-6924.2008.01010.x.

Kempton, W., 1991: Lay perspectives on global climate change. Global Environ. Change, 1, 183-208, https://doi.org/10.1016/ 0959-3780(91)90042-R.

Krause, N. M., D. Brossard, D. A. Scheufele, M. A. Xenos, and K. Franke, 2019: Trends-Americans' trust in science and scientists. Public Opin. Quart., 83, 817-836, https://doi.org/ 10.1093/poq/nfz041.

Leiserowitz, A. A., E. W. Maibach, C. Roser-Renouf, N. Smith, E. Dawson, 2012: Climategate, public opinion, and the loss of trust. Amer. Behav. Sci., 57, 818-837, https://doi.org/10.1177/ 0002764212458272

Levay, K. E., J. Freese, and J. N. Druckman, 2016: The demographic and political composition of Mechanical Turk samples. SAGE Open, 6, 1-17, https://doi.org/10.1177/2158244016636433.

Levine, A. S., and R. Kline, 2017: A new approach for evaluating climate change communication. Climatic Change, 142, 301-309, https://doi.org/10.1007/s10584-017-1952-x.

—, and _ 2019: Loss-framed arguments can stifle political activism. J. Exp. Pol. Sci., 6, 171-179, https://doi.org/10.1017/XPS.2018.28.

Lubell, M., S. Zahran, and A. Vedlitz, 2007: Collective action and citizen responses to global warming. Polit. Behav., 29, 391413, https://doi.org/10.1007/s11109-006-9025-2.

Lupia, A., 2013: Communicating science in politicized environments. Proc. Natl. Acad. Sci. USA, 110, $14048-14054$, https:// doi.org/10.1073/pnas.1212726110.

Ma, Y., G. Dixon, and J. D. Hmielowski, 2019: Psychological reactance from reading basic facts on climate change: The role of prior views and political identification. Environ. Commun., 13, 71-86, https://doi.org/10.1080/17524032.2018.1548369.

McCright, A. M., K. Dentzman, M. Charters, and T. Dietz, 2013: The influence of political ideology on trust in science. Environ. Res. Lett., 8, 044029, https://doi.org/10.1088/1748-9326/8/4/044029.

McGrath, M. C., 2020: Experiments on problems of climate change. Advances in Experimental Political Science, J. N. Druckman and D. P. Green, Eds., Cambridge University Press, in press.

Mildenberger, M., and D. Tingley, 2019: Beliefs about climate beliefs: The importance of second-order opinions for climate politics. Br. J. Polit. Sci., 49, 1279-1307, https://doi.org/ 10.1017/S0007123417000321.

Milkoreit, M., M.-L. Moore, M. Schoon, and C. L. Meek, 2015: Resilience scientists as change-makers-Growing the middle ground between science and advocacy? Environ. Sci. Policy, 53, 87-95, https://doi.org/10.1016/j.envsci.2014.08.003.

Motta, M., 2018: The polarizing effect of the March for Science on attitudes toward scientists. PS Polit. Sci. Polit., 51, 782-788, https://doi.org/10.1017/S1049096518000938.

Mullin, M., 2017: Will the March for Science backfire by politicizing science? It depends on this. Washington Post, 21 April, https://www.washingtonpost.com/news/monkey-cage/wp/2017/ 04/21/the-march-for-science-could-backfire-by-politicizing-sciencethis-might-help/.

Mullinix, K., T. Leeper, J. Druckman, and J. Freese, 2015: The generalizability of survey experiments. J. Exp. Pol. Sci., 2, 109-138, https://doi.org/10.1017/XPS.2015.19.

Nielsen, K. S., S. Clayton, P. C. Stern, T. Dietz, S. Capstick, and L. Whitmarsh, 2020a: How psychology can help limit climate change. Amer. Psychol., https://doi.org/10.1037/amp0000624, in press.

— S. van der Linden, and P. C. Stern, 2020b: How behavioral interventions can reduce the climate impact of energy use. Joule, 4, 1613-1616, https://doi.org/10.1016/j.joule.2020.07.008.

Nisbet, E. C., K. E. Cooper, and R. K. Garrett, 2015: The partisan brain: How dissonant science messages lead conservatives and liberals to (dis)trust science. Ann. Amer. Acad. Pol. Soc. Sci., 658, 36-66, https://doi.org/10.1177/0002716214555474.

Pennycook, G., J. McPhetres, B. Bago, and D. G. Rand, 2020: Predictors of attitudes and misperceptions about COVID-19 in Canada, the U.K., and the U.S.A. PsyArXiv, 33 pp., https:// doi.org/10.31234/osf.io/zhjkp.

Perlmuter, L. C., K. Scharff, R. Karsh, and R. A. Monty, 1980: Perceived control: A generalized state of motivation. Motiv. Emot., 4, 35-45, https://doi.org/10.1007/BF00995928.

Pew Research Center, 2018: Majorities see government efforts to protect the environment as insufficient. PRC, http://www.pewresearch.org/ science/2018/05/14/majorities-see-government-efforts-to-protectthe-environment-as-insufficient/.

Poore, J., and T. Nemecek, 2018: Reducing food's environmental impacts through producers and consumers. Science, 360, 987-992, https://doi.org/10.1126/science.aaq0216.

Safford, T. G., E. H. Whitmore, and L. C. Hamilton, 2019: Questioning scientific practice: Linking beliefs about scientists, science agencies, and climate change. Environ. Sociol., 6, 194-206, https://doi.org/10.1080/23251042.2019.1696008.

Sterman, J. D., and L. B. Sweeney, 2007: Understanding public complacency about climate change: Adults' mental models of climate change violate conservation of matter. Climatic Change, 80, 213-238, https://doi.org/10.1007/s10584-006-9107-5.

Stern, P. C., 2020: A reexamination on how behavioral interventions can promote household action to limit climate change. Nat. Commun., 11, 918, https://doi.org/10.1038/s41467-020-14653-x.

Van Bavel, J. J. V., and Coauthors, 2020: Using social and behavioural science to support COVID-19 pandemic response. Nat. Hum. Behav., 4, 460-471, https://doi.org/10.1038/s41562-020-0884-z.

Van Boven, L., P. J. Ehret, and D. K. Sherman, 2018: Psychological barriers to bipartisan public support for climate policy. Perspect. Psychol. Sci., 13, 492-507, https://doi.org/10.1177/1745691617748966.

van der Linden, S., 2016: The social-psychological determinants of climate change risk perceptions, attitudes, and behaviours: A national study. Environ. Educ. Res., 22, 434-435, https:// doi.org/10.1080/13504622.2015.1108391.

_ 2017: Determinants and measurement of climate change risk perception, worry, and concern. The Oxford Encyclopedia of Climate Change Communication, M. C. Nisbet et al., Eds., Oxford University Press, https://doi.org/10.1093/acrefore/ 9780190228620.013.318.

Whitmarsh, L., 2009: Behavioural responses to climate change: Asymmetry of intentions and impacts. J. Environ. Psychol., 29, 13-23, https://doi.org/10.1016/j.jenvp.2008.05.003.

Zahran, S., S. D. Brody, H. Grover, and A. Vedlitz, 2006: Climate change vulnerability and policy support. Soc. Nat. Resour., 19, 771-789, https://doi.org/10.1080/08941920600835528. 